\title{
Efeito de diferentes soluções ácidas na corrosão de Arcos Niti ou Aço
}

\section{Effect of different acid solutions on the corrosion of NiTi or Steel archwire}

\section{RESUMO}

Corrosão é um processo natural que ocorre quando um metal entra em contato com soluções ácidas. Esse fenômeno provoca danos estruturais aos fios ortodônticos de ligas de NiTi e Aço inoxidável.

Trinta amostras com $10 \mathrm{~mm}$ de comprimento, obtidas de arcos superiores de NiTi superelástico e de arcos de Aço, embebidos em ácido cítrico industrializado, solução de sprite e à base de cola. Cada grupo de solução foram embebidas, por 90 minutos, 05 unidades de segmentos de fio de cada liga, por 21 dias consecutivos, compondo 6 grupos experimentais. Após esse procedimento, analisou as amostras por microscopia eletrônica de varredura (MEV).

Palavras-chave: Corrosão, Fios Ortodônticos, Soluções Ácidas, NiTi.

Palabras clave: Corrosión, Alambre de Ortodoncia, Soluciones Ácidas, NiTi.

\section{ABSTRACT}

Corrosion is a natural process which happens when one metal interact with an acid solution. This reaction results in structural damage to the orthodontic wires of NiTi and in the Stainless steel arches.

Thirty samples of $10 \mathrm{~mm}$ obtained from upper arcs of NiTi superplastic and from steel arcs, soaked in industrialised citric acid, sprite solution and cola. Each sample was soaked for 90 minutes, 5 units of each segment for 21 consecutive days, containing 6 experimental groups. At the end of this experiment the samples were analysed for scanning electron microscopy.

Keyword: Corrosion, Orthodontic Wire, Acid Solution, NiTi.

\section{Leticia Feitosa de Oliveira ${ }^{1}$}

Lucas Hian da Silva ${ }^{2}$

Fernando Akio Maeda ${ }^{2}$

Tarcila Triviño ${ }^{2}$

${ }^{1}$ Aluna do Curso de graduação em Odontologia, Universidade Cidade de São Paulo.

${ }^{2}$ DDS, MsC, PhD. Professor Curso de lato sensu em Odontologia, Universidade Cidade de São Paulo.

Autor para correspondência:

Nome do autor: Tarcila Triviño

Endereço: Avenida Nove de Julho, 5483, conj

111 - Jardim Paulista - São Paulo - CEP 01407200

Telefone: (11) 981961120 


\section{INTRODUÇÃO}

O sistema arcos-bráquetes são frequentemente utilizados na ortodontia, com a intenção de obter a movimentação dentária ${ }^{1}$. Para essa movimentação dentária seja mais eficiente e fisiológica durante as fases iniciais de nivelamento e alinhamento, esse sistema deve gerar baixas forças ortodônticas, mas de modo contínuo e dentro dos limites fisiológicos. ${ }^{2,3}$

Com isso, as ligas de níquel com titânio (NiTi) têm sido amplamente utilizadas por conta da sua biocompatibilidade e as suas propriedades mecânicas como: efeito de memória da forma e superelásticidade ${ }^{4}$. As ligas de NiTi conseguem retornar à sua forma originalmente definida quando deformadas em até $8 \%$. Porém, os arcos de NiTi apresentam baixa resistência à corrosão diante dos íons de flúor e também pelo $\mathrm{pH} .^{5}$

Evolução histórica dos fios de NiTi Em 1963, surge nos EUA, a liga de NiTi. O pesquisador em metalurgia William Buehler, desenvolveu uma liga com características únicas que possui um baixo módulo de elasticidade, rigidez e alta resiliência. ${ }^{6}$

A Unitek Corporation, em 1972, produziu fios a partir desta liga para o uso clínico em ortodontia, com o nome comercial de Nitinol, composto por 55\% de níquel e $45 \%$ de titânio. E foi considerado um avanço para a obtenção de forças leves sob grandes ativações, ganhando ampla aceitação entre os ortodontistas. Apesar de possuir excelente propriedade de recuperação elástica, o Nitinol não possuía, naquela época, o efeito de memória de forma. ${ }^{7}$

As ligas de NiTi superelásticas (NiTi SE) foram inicialmente produzidas em 1978 pela empresa Furukawa Eletric Co., do Japão. E seu aprimoramento aconteceu em 1986, com o lançamento do Japanese NiTi.$^{8}$

Outra liga que merece nossa atenção é a Chinese NiTi, desenvolvida por Tien Huan Cheng. Essa liga possuía uma característica única de manutenção dos níveis de força durante a ativação e desativação. ${ }^{9}$

Na década de 90 surgiram no mercado fios NiTi termoativados que além de possuírem as características dos fios anteriores, também eram ativados pela temperatura. $\mathrm{Na}$ mesma década surgiu o fio de CuNiTi. A introdução do cobre garantiu a liga de NiTi uma temperatura de transição mais definida, deixando a liberação de cargas mais homogêneas por todo o fio. 6,10

A demanda por estética fez as empresas a desenvolverem os primeiros fios de NiTi estéticos em meados do século XXI. Esses fios receberam uma camada de material polimérico, que podia ser de teflon ou de resina epóxi. E essa cobertura dava ao fio características mais estéticas. E esta tecnologia permitiu agregar aos fios de NiTi além da cor branca qualquer outro tipo de cor. ${ }^{11}$

Os arcos de liga aço inoxidável permitem dobras são utilizados em bandas, bráquetes e fios ortodônticos que são feitos de aproximadamente de $8 \%$ a $12 \%$ de níquel, $17 \%$ a $22 \%$ de cromo e proporções variadas de manganês, titânio, ferro e cobre. O cromo é responsável pela resistência à corrosão apresentada por esses tipos de fios. ${ }^{12}$

O processo fisiológico da movimentação é quase impossível de ser representado clinicamente. Estudos revelam que, forças contínuas e de intensidade leve são mais efetivas do que forças pesadas e intermitentes. ${ }^{13}$ 
Contudo, o fio ortodôntico de ligas de aço tem uma movimentação ortodôntica que interage com diversos fatores, dos quais englobam as características biológicas, biomecânicas e propriedade mecânica dos fios que apresenta dureza, atrito e módulo de elasticidade. A sua resistência a corrosão se dá por formação de uma finíssima camada de óxido de cobre sobre a superfície, porém essa camada pode ser destruída por agressões mecânicas ou químicas. ${ }^{14}$

A corrosão é um processo natural que ocorre quando um metal se encontra em contato com soluções ácidas. Na ortodontia, esse fenômeno provoca danos estruturais aos fios ortodônticos de ligas de NiTi e aço inoxidável, aumentando a rugosidade de superfície ${ }^{15,}$ 8 , afetando no atrito do conjunto arco-bráquete, influenciando na eficácia do tratamento, além de também poder iniciar reações tóxicas e alérgicas pela liberação do níquel. ${ }^{16,17}$

Diversos são os fatores que podem interferir no processo de liberação de iônica de uma liga: a fabricação, o tipo de liga, características do meio, temperatura, pH, dentre outros. ${ }^{10}$ A adição dos ácidos aos refrigerantes, reduz o pH e restringe a contaminação, esses ácidos atuam como conservadores e propiciam um sabor típico da bebida. Entre esses ácidos os mais utilizados são: fosfórico, cítrico, fumárico, málico e tartárico. ${ }^{18}$

O refrigerante Sprite possui um pH 1,86, o qual está entre os que apresentaram o maior potencial erosivo, tal influência do seu $\mathrm{pH}$ sobre as superfícies dentárias foram comprovadas pelo aumento da rugosidade da resina composta. ${ }^{19}$

Sendo assim o consumo de substâncias ou soluções ácidas durante o tratamento ortodôntico, como soluções à base de ácido cítrico industrializado que apresentam um pH entre 2,4 a 3,1 e as soluções à base de cola que possui um $\mathrm{pH}$ de 2,5, poderia ocasionar danos ao aparelho ortodôntico e diminuir a sua eficácia.

Objetivo: avaliar o efeito da corrosão dos arcos de NiTi e de Aço inoxidável quando embebidos em soluções ácidas á base de ácido cítrico e à base de cola. Dessa maneira, mostrar a importância que há em conhecer as propriedades dos fios ortodônticos que estão disponiveis no mercado. Com isso, influenciar na escolha do material, e assim contribuir na qualidade do tratamento ortodôntico.

\section{MATERIAIS E MÉTODOS}

Para o presente estudo foi o, inicialmente, adquiridos 11 arcos superiores de $\mathrm{NiTi}$ superelástico $\left(0.017^{\prime \prime} \times 0.025^{\prime \prime}\right)$ e 11 de arcos de aço $\left(0.017^{\prime \prime} \times 0.025^{\prime \prime}\right)$ da marca comercial Orthometric (Marilia - SP), dos quais foram obtidos segmentos distais desses fios com $10 \mathrm{~mm}$ de comprimento.

Os 30 segmentos de arco foram divididos em dos grupos: Grupo 1 ( $n=10)$ - composto por segmentos que a serem embebidos em solução de ácido cítrico industrializado (5 unidades de liga NiTi e 5 unidades de liga aço inoxidável); e Grupo 2 - composto por segmentos que a serem embebidos em refrigerante Sprite; Grupo 3 - composto por segmentos que a serem embebidos em refrigerantes à base de cola ( 5 unidades de liga NiTi e 5 unidades de liga aço inoxidável). Dessa forma obteve se 6 grupos experimentais juntamente com 1 amostra de cada tipo de fio que não sofreu o experimento.

Os de cada grupo segmentos de arco foram expostos às suas respectivas soluções ácidas (recipientes pequenos com 40ml) por um período de 90 minutos/dia por 21 dias 
consecutivos. Nos intervalos aos mergulhos, os espécimes eram mantidos em estufa contendo água destilada a $37^{\circ} \mathrm{C}$, representando a cavidade bucal.

Após o desafio, todas as amostras foram enxaguadas em água deionizada por 30 s, seguido em imersão em ultrassom (Unique - Ultra cleaner 1.400), secos então em papel absorvente e ar comprimido.

Com a obtenção da amostra e anterior ao embebimento nas três soluções, os segmentos de arcos tiveram o seu perfil topográfico analisado em microscopia eletrônica de varredura (MEV). As imagens obtidas serão analisadas e comparadas com as obtidas ao início do experimento.

\section{DESAFIOS DAS AMOSTRAS}

Os trinta segmentos de arco foram divididos em grupos:

Grupo $1(\mathrm{n}=10)$ - composto por segmentos embebidos em solução de ácido cítrico industrializado ( 5 unidades de liga NiTi e 5 unidades de liga aço inoxidável);

Grupo 2 - composto por segmentos embebidos em refrigerante de limão (5 unidades de liga NiTi e 5 unidades de liga aço inoxidável);

Grupo 3 - composto por segmentos embebidos em refrigerantes à base de cola (5 unidades de liga NiTi e 5 unidades de liga aço inoxidável).
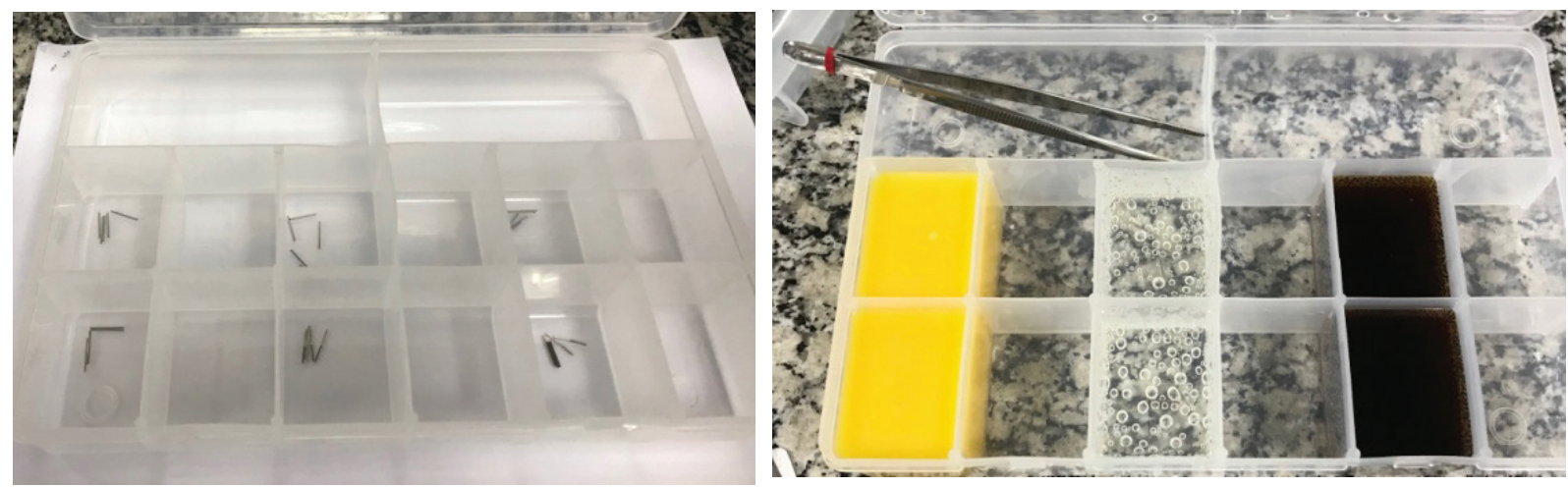

Figura 1 - Imagens que demonstram a separação de cada grupo, seus respectivos fios e as soluções.

Durante vinte e um dias consecutivos as amostras receberam $40 \mathrm{ml}$ de sua determinada solução, no qual ficavam por um ciclo de 90 minutos embebidas. Após tal ciclo eram lavadas, e mantidas em uma estufa de temperatura correspondente a $37^{\circ} \mathrm{C}$, na qual ficavam embebidas em água destilada.

Concluído os 21 dias ininterruptos, todas as amostras foram enxaguadas em água deionizada por 30 segundos e, secos então em papel absorvente.

De forma aleatória, foi escolhida uma amostra de cada grupo para comparação ao microscópio eletrônico de varredura (MEV - JEOL. JCM-5000) sendo ao todo 8 fios analisados, que mostram a rugosidade das soluções relacionadas aos fios. (Figura 3) 

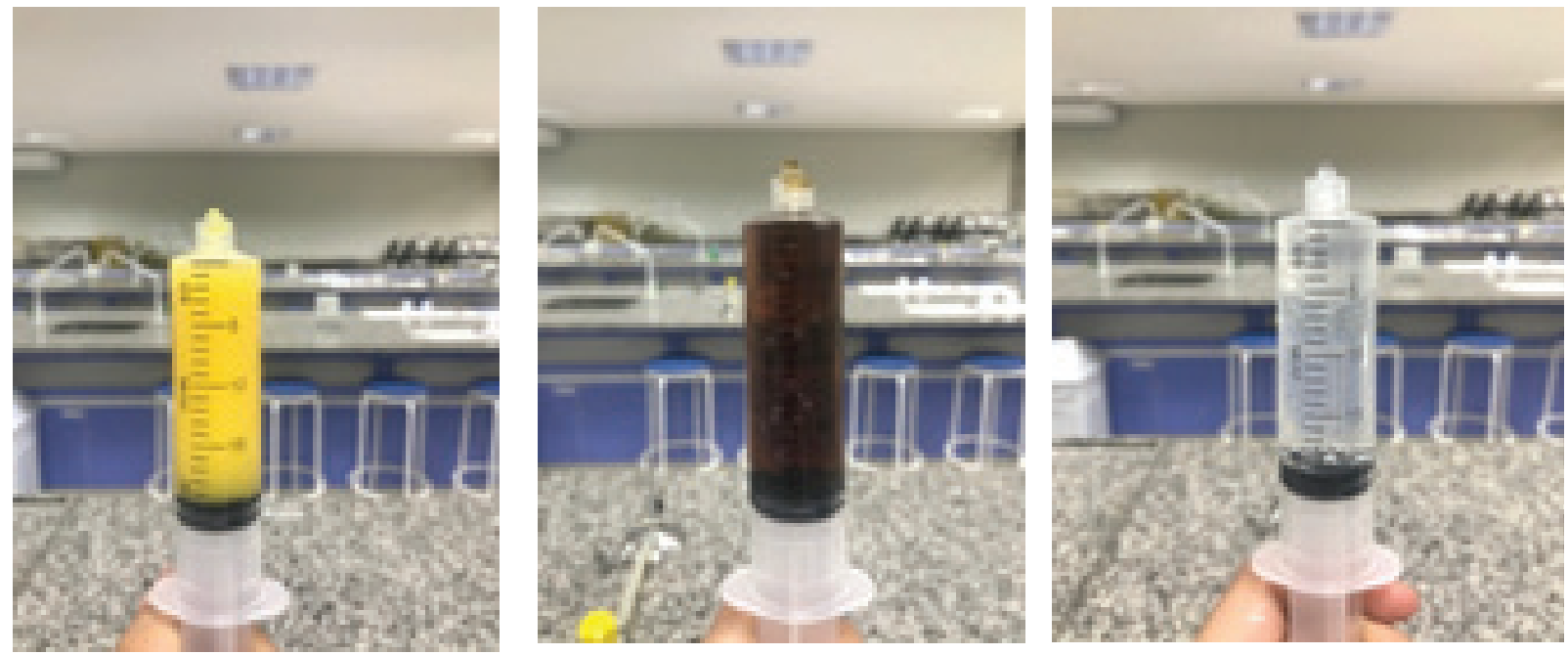

Figura 2 - Imagens que representam a quantidade em que cada solução para o embebimento dos fios.
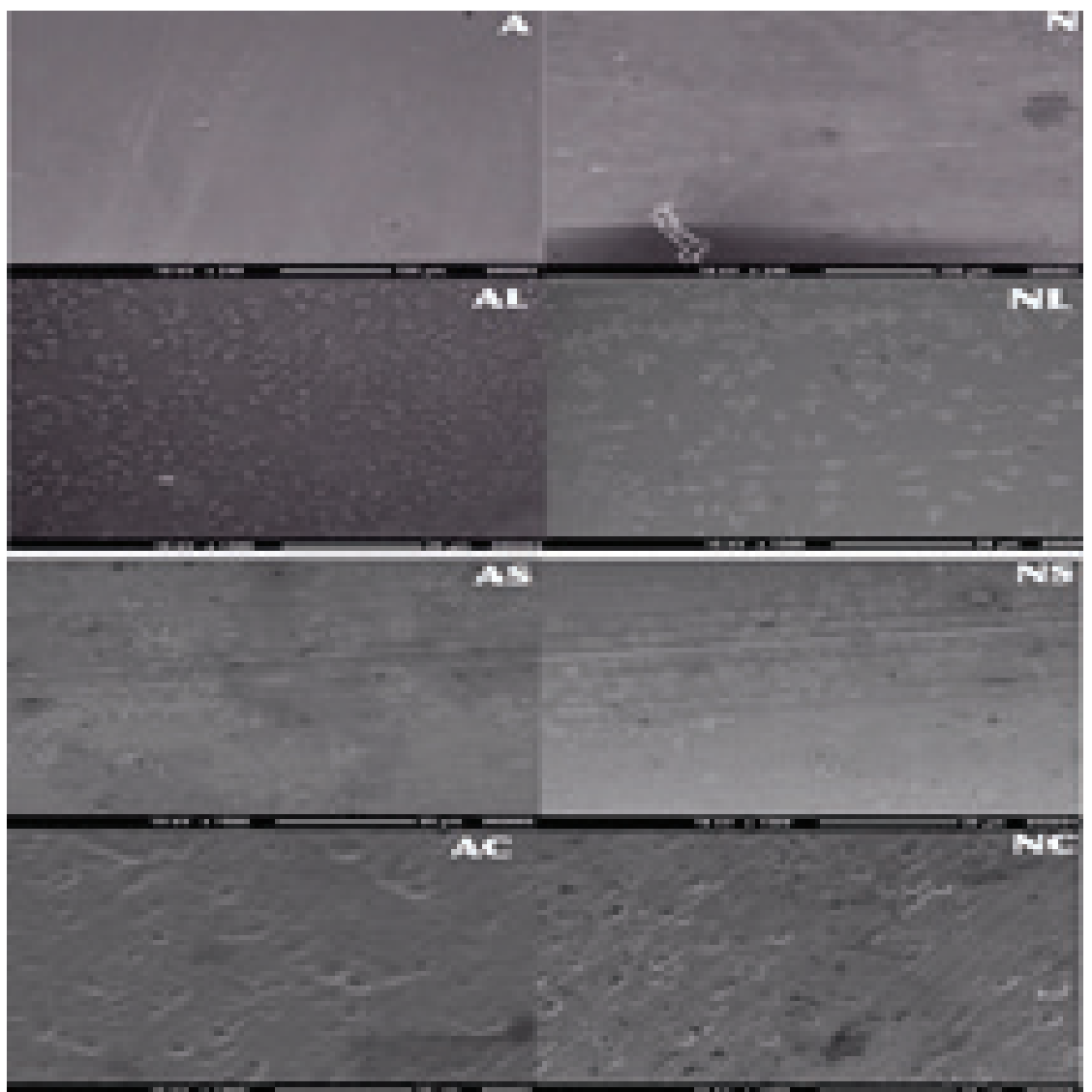

Figura 3- Imagem dos fios feita pelo microscópio eletrônico de varredura (MEV - JEOL. JCM-5000) após a experiência dos 21 dias consecutivos, antes da lavagem em água deionizada no ciclo de 10 minutos. É possível analisar a capacidade da superfície dos fios, que se torna rugoso.

Legenda: A: será referente ao Fio de Aço Inoxidável puro, N: Fio NiTi puro, AL: Fio de Aço Inoxidável que estava embebido em solução de ácido cítrico industrializado,

NL: Fio de NiTi embebido em solução de ácido cítrico industrializado, AS: Fio de Aço Inoxidável embebido em refrigerante Sprite, NS: Fio de NiTi embebido em refrigerante Sprite, AC: Fio de Aço Inoxidável embebido em refrigerantes à base de cola, NC: Fio de NiTi embebido em refrigerantes à base de cola. 
Após isso, os espécimes todos os espécimes foram lavados no Ultrassom (Kondortech Digital Ultrassonic Cleaner). Conforme separada em grupos, foram colocados em um Becker e imersos em água deionizada, e assim, submetidos a um ciclo de 10 minutos Desta forma, os oito fios novamente passaram pelo microscópio varredura eletrônica (MEV - JEOL. JCM-5000) no qual foi possível observar as corrosões do experimento (Figura 4).

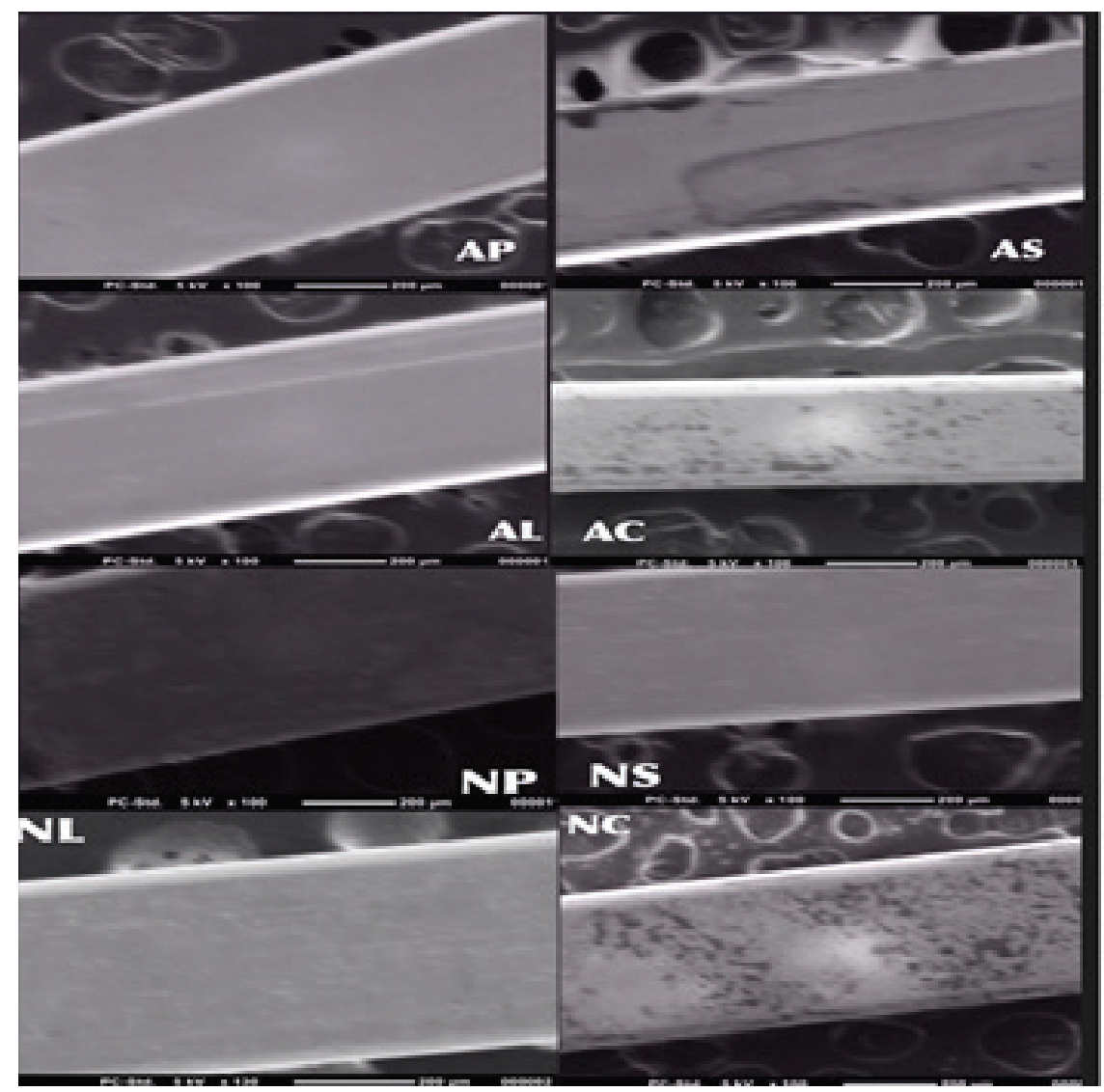

Figura 4 - Imagem dos fios feita pelo microscópio eletrônico de varredura (MEV - JEOL. JCM-5000) após a lavagem na água deionizada no ciclo de 10 minutos. Dessa forma, é possível notar que todos os fios tendem a sofrer esse processo de corrosão e as imagens mostram que os fios AC (aço inoxidável embebido em solução a base de cola) a e NC (NiTi embebido em solução a base de cola) foram os que mais sofreram os efeitos dessa solução ácida.

\section{RESULTADOS}

As imagens iniciais geradas pelo MEV com o aumento de 1.500 x mostram que houve corrosão, tanto no fio de Aço Inoxidável como no Fio de Liga de Titânio.

Nas três soluções é possível notar o poder da adesão das substâncias em ambos os fios, o que mais adiante mostrarão a interferência na conformação do fio, mesmo sendo estes, estruturalmente distintos.

Baseado na Figura 3, todas as soluções possuíram uma boa rugosidade e aderência nos fios metálicos, sendo este um fator contribuinte no nível de corrosão. 


\section{DISCUSS ÃO}

O trabalho teve como objetivo analisar a resistência à corrosão das ligas utilizadas em arcos de ortodontia, as quais dependem do meio ambiente oral, que também sofre interferência de diversas variáveis, tais como a temperatura, a quantidade e qualidade da saliva, a placa, $\mathrm{pH}$, propriedades dos alimentos sendo estes sólidos/líquidos.

Para Robert D. Barrett, D., MS, B. Samir E. Bishara, D. Ortho, DDS, MS, and B. Janice K. Quinn, (2000), concluíram que diversos aparelhos de ortodontia contêm ligas de cromo $(\mathrm{Cr})$, cobalto $(\mathrm{Co})$, níquel $(\mathrm{Ni})$ e titânio $(\mathrm{Ti})$. A cavidade oral é, particularmente, ideal para a biodegradação de metais devido ao seu potencial iónico, condições térmicas, flora microbiana e propriedades enzimáticas, sendo exposto à degradação daqueles materiais e respectivos produtos de corrosão ${ }^{20}$ Este trabalho confirma isso, pois a temperatura na cavidade oral, a qual foi simulada pela Estufa, formou esse ambiente para a biodegradação dos metais, na qual teve uma influência sobre o processo corrosivo, o que induziu o $\mathrm{pH}$ e as suas modificações acarretem diretamente o processo corrosivo dos arcos.

\section{CONCLUSÃO}

Na primeira analise dos fios que não passaram pelo Ultrassom, é possível saber que existiu um processo corrosivo nos arcos de ortodontia, independente da liga metálica que os compõe.

Em ambos, tal dano parece não resultar em efeitos prejudiciais significativos sobre as propriedades, pois de imediato não acarretou na destruição significativa dos componentes metálicos.

Mesmo o fio de Aço inoxidável ter ligas com Cr-Co (Crómio e cobalto) em sua formação ter uma película superficial de óxido passiva para resistir à corrosão essa película não mostrou se capaz de resistir totalmente aos danos das soluções químicas /líquidos.

Os fios mais danificados, baseado nas imagens feita pelo microscópio eletrônico de varredura mostraram que os fios AC (Aço inoxidável embebido em solução a base de cola) a e NC (NiTi embebido em solução a base de cola) foram os que mais sofreram os efeitos dessa solução ácida.

Todos os fios estão susceptíveis ao dano. Nenhum sairá ileso do processo de corrosão mesmos com diferentes níveis de $\mathrm{pH}$ atuando sobre o fio.

\section{REFERÊNCIAS}

1. Schiff N, Boinet M, Morgon L, Lissac M, Dalard F, Grosgogeat B. Galvanic corrosion between orthodontic wires and brackets in fluoride mouthwashes. European journal of orthodontics. 2006;28(3):298-304.

2. Persson M. A 100th anniversary: Sandstedt's experiments on tissue changes during tooth movement. Journal of orthodontics. 2005;32(1):27-8.

3. Sandhu SS, Shetty VS, Mogra S, Varghese J, Sandhu J, Sandhu JS. Efficiency, behavior, and clinical properties of superelastic NiTi versus multistranded stainless steel wires: a prospective clinical trial. The Angle orthodontist. 2012;82(5):915-21.

4. Kusy RP. A review of contemporary archwires: their properties and characteristics. The Angle orthodontist. 1997;67(3):197-207.

5. Dayananda GN, Subba Rao M. Effect of strain rate on properties of superelastic NiTi thin wires. Mater Sci Eng A Struct Mater. 2008;486(1-2):8. 
6. Imai T, Watari F, Yamagata S, Kobayashi M, Nagayama K, Nakamura S. Effects of water immersion on mechanical properties of new esthetic orthodontic wire. Am J Orthod Dentofacial Orthop. 1999;116:553-538

7. Andreasen GF, Hilleman TB. An evoluation of 55 cobalt substituted Nitinol wire for use in orthodontics. J Am Dent Assoc. 1971;82(6):1373-5

8. Kusy RP. A review of contemporary archwires: their properties and characteristics. Angle Orthod, 1997;67(3):197-208.

9. Miura F, Mogi M, Ohura Y, Hamanaka H. The super-elastic property of Japanese NiTi alloy wire for use in orthodontics. Am J Orthod Dentofacial Orthop.1986;90(1):1-10.

10. Menezes LM, Souza RM, Dolei GS, Dedavid BA. Biodegradação de braquetes ortodônticos: análise por microscopia eletrônica de varredura. 2010 May-June;15(3);48-51

11. Gravina MA, Canavarro C, Elias CN, Chaves MGAM. Brunharo IHVP, Quintão CCA. Mechanical properties of NiTi and CuNiTi wires used in orthodontic 36treatment. Part 2: Microscopc surface appraisal and metallurgical characteristics. Dental Press J Orthod. 2014;19(1):69-76

12. Gürsoy S, Acar AG, Seşen C. Comparison of metal release from new and recycled bracket-archwire combinations. Angle Orthod. 2005 Jan;75(1):92-4.

13. Ferreira E.S, Mundstock C.A, Müller C.M. The use of wires in orthodontic. R.Fac. Odontol.- Porto Alegre - v. 39- n. 1 -p. 23-30 - Julho 1998.

14. Staffolani N, Damiani F, Lilli C, Guerra M, Staffolani NJ, Belcastro S, Locci P. Ion release from orthodontic appliances. J Dent. 1999 Aug;27(6):449-54.

15. Huang HH. Effects of fluoride concentration and elastic tensile strain on the corrosion resistance of commercially pure titanium. Biomaterials. 2002;23(1):5.

16. Kao CT, Ding SJ, He H, Chou MY, Huang TH. Cytotoxicity of orthodontic wire corroded in fluoride solution in vitro. The Angle orthodontist. 2007;77(2):349-54

17. Kassab EJ, Gomes JP. Assessment of nickel titanium and beta titanium corrosion resistance behavior in fluoride and chloride environments. The Angle orthodontist. 2013;83(5):864-9.

18. Celestino, Sonia Maria Costa. Produção de refrigerantes de frutas - Planaltina, DF : Embrapa Cerrados, 2010.29 p. - (Documentos / Embrapa Cerrados, ISSN 1517-5111, ISSN online 2176-5081 ; 279).1. Fruta. 2. Refrigerante - produção. I. Título. II. Série

19. Jovito Adiel Skupien et al. Avaliação do pH de refrigerantes do tipo normal e light. Saúde, Santa Maria, vol 35,n.2; p.33 - 36, 2009.

20. Robert D. Barrett, D., MS, B. Samir E. Bishara, D. Ortho, DDS, MS, and B. Janice K. Quinn, Biodegradation of orthodontic apliances. Biodegradation of nickel and chromium in vitro. American Journal of Orthodontics and Dentofacial Orthopedics, January 2000. 103(1): p. 8- 14. 